\title{
Relationships between macro-fungal dark diversity and habitat parameters using LiDAR
}

\author{
Jose W. Valdez ${ }^{1}$, Ane Kirstine Brunbjerg ${ }^{1}$, Camilla Fløjgaard ${ }^{1}$, Lars Dalby ${ }^{1}$, Kevin K. \\ Clausen ${ }^{1}$, Meelis Pärtel ${ }^{2}$, Norbert Pfeifer ${ }^{3}$, Markus Hollaus ${ }^{3}$, Michael H. Wimmer ${ }^{3}$, Rasmus \\ Ejrnæs $^{1}$, Jesper Erenskjold Moeslund ${ }^{1 *}$ \\ ${ }^{1}$ Department of Bioscience, Aarhus University, Grenåvej 14, 8410, Rønde, Denmark \\ ${ }^{2}$ Department of Botany, Institute of Ecology and Earth Sciences, University of Tartu, Lai 40, \\ Tartu, 51005, Estonia \\ 3 Department of Geodesy and Geoinformation, Technische Universität Wien, Wiedner \\ Hauptstraße 8/E120, 1040 Vienna, Austria \\ *Corresponding author. Email: jesper.moeslund@bios.au.dk
}

\begin{abstract}
Despite the important role of fungi for ecosystems, relatively little is known about the factors underlying the dynamics of their diversity. Moreover, studies do not typically consider their dark diversity: the species absent from an otherwise suitable site. Here, we examined potential drivers of local fungal dark diversity in temperate woodland and open habitats using LiDAR and in-situ field measurements, combined with a systematically collected and geographically comprehensive macro-fungi and plant data set. For the first time, we also estimated species pools of fungi by considering both plant and fungi co-occurrences. The most important LiDAR variables for modelling fungal dark diversity were amplitude and echo ratio, which are both thought to represent vegetation structure. These results suggest that the local fungal dark diversity is highest in production forests like plantations and lowest in more open forests and in open habitats with little woody vegetation. Plant species richness was the strongest explanatory factor overall and negatively correlated with local fungal dark diversity. Soil fertility showed a positive relationship with dark diversity in open habitats. These findings may indicate that the local dark diversity of macro-fungi is highest in areas with a relatively high human impact (typically areas with low plant species richness and high soil fertility). Overall, this study brings novel insights into local macro-fungi dark diversity patterns, suggesting that a multitude of drivers related to both soil and vegetation act in concert to determine fungal dark diversity.
\end{abstract}


31 Key Words: airborne laser scanning, bog, fens, forests, fungal diversity, grasslands,

32 mycorrhiza, regional species pool, remote sensing, shrublands, wetlands

\section{Introduction}

Understanding the underlying drivers shaping biodiversity patterns is a central goal in ecology and conservation biology. This is also true for fungi which play a vital role in ecosystem functioning as decomposers, mutualists, and pathogens. However, fungi and the underlying environmental factors influencing fungal diversity is less studied than animals and plants, and quantifying fungal diversity is far from trivial. The most commonly used biodiversity metric is observed species richness (Mueller 2011). However, this measure is not always suitable for comparisons across habitats and conveys no information on the part of the diversity that is potentially missing in a given site (Pärtel et al. 2011). In addition, monitoring

42 fungal diversity is often severely hampered by detectability issues and the life history of the 43 involved species (Yahr et al. 2016, Blackwell and Vega 2018). Several alternative 44 approaches have been developed to more effectively monitor and compare biodiversity across 45 landscapes (Solow and Polasky 1994, Sarkar and Margules 2002, Ricotta 2005, Ricotta 46 2007). Although these methods can provide valuable insights, they do not consider the dark 47 diversity, the absent part of the species pool which can potentially inhabit an environmentally 48 suitable site (Pärtel et al. 2011). This often-ignored aspect of diversity provides a novel and ecologically meaningful metric for estimating how much of the potential species diversity the site-specific species pool - is lacking (Pärtel et al. 2011). This information is important to understand the underlying mechanisms and dynamics of community assembly (e.g., community saturation) (Mateo et al. 2017). Dark diversity may also become an important conservation tool to measure biodiversity potential, such as aiding managers or policy-makers to prioritize certain habitats, estimate restoration potential of degraded habitats, or forecast potential impacts of invasions (Lewis et al. 2017). Here, we use fungal data from 130 thoroughly inventoried sites covering all terrestrial habitats, from open to forest, and wet to arid, to investigate important drivers of fungal dark diversity.

Dark diversity aims to reconcile the role of simultaneous, and potentially confounding, regional and local processes underlying biodiversity patterns and biological communities (Pärtel et al. 2011, Pärtel 2014). In any given landscape, the biodiversity

61 potential is ultimately determined by large-scale biogeographic and evolutionary processes 62 (i.e., species diversification and historic migration patterns) determining the set of species 
63 which can theoretically inhabit a site, defined as the regional pool (Pärtel et al. 1996, Cornell 64 and Harrison 2014, Zobel 2016). This regional pool is further filtered by local processes such

65 as environmental gradients, species interactions, population dynamics, dispersal, disturbance,

66 and stochastic events and referred to as the site-specific species pool, i.e., species that could

67 possibly live in a given site (Pärtel et al. 2013, Cornell and Harrison 2014, Ronk et al. 2015,

68 Zobel 2016). While many studies have investigated the drivers of fungal diversity, only a few

69 studies have focused on the determinants of fungal dark diversity. These studies demonstrate

70 that higher temperatures increases arbuscular mycorrhizal dark diversity (Pärtel et al. 2017a)

71 and annual precipitation decreases the dark diversity of ectomycorrhizal fungi at the global

72 scale (Pärtel et al. 2017b). These results concur with previous research suggesting that large

73 scale climatic factors are strong drivers of fungal richness and community composition,

74 attributed to the direct and indirect effects which alter soil and floristic conditions (Staddon et

75 al. 2003, Kivlin et al. 2011, Tedersoo et al. 2014). Local edaphic conditions such as soil

76 moisture, $\mathrm{pH}$, and calcium concentration are also known to influence fungal diversity (Geml

77 et al. 2014, Tedersoo et al. 2014, Tonn and Ibáñez 2017, Frøslev et al. 2019), but it is not

78 known how these environmental factors affect fungal dark diversity. In fact, the general

79 mechanisms determining dark diversity in fungal communities remain largely unknown.

80 Clearly, species can be absent from an area just by chance (Hubbell 2011). Species can also

81 be absent from a site because of some kind of unexpected disturbance - for example human,

82 but it could also be natural - altering species' dispersal, establishment, or persistence

83 possibilities. In principle, these disturbances can be both biological and chemical and act at

84 various spatial scales. An example could be extreme drought. Often habitats have a constant

85 level of relatively low or usual disturbances that the habitat's species are adapted to (e.g.,

86 grazing), and these do not count towards disturbances that can cause dark diversity. It is

87 important not to confuse dark diversity with hidden diversity; i.e., species that are actually

88 present in a given site but just not recorded (Milberg et al. 2008, Abrego et al. 2016).

89 Besides the influence of environmental gradients, other factors particularly important

90 for fungi are vegetation and habitat structure, such as vegetation height, shrub layer,

91 vegetation cover, dead wood, and other woody features (Humphrey et al. 2000, Nordén and

92 Paltto 2001, Nordén et al. 2004, Gómez-Hernández and Williams-Linera 2011, Zuo et al.

93 2016). As the dominant primary producer in terrestrial ecosystems, plants also form the living

94 and dead organic carbon pools and biotic surfaces that are the niche space for not only fungi

95 but other taxonomic groups as well (DeAngelis 2012, Brunbjerg et al. 2017). These structural 
96 elements are an important element for biodiversity, and can influence not only fungal 97 diversity, but the diversity of plants, animals, and bacteria as well (Penone et al. 2019).

98 However, despite the obvious contribution of these variables, such factors are rarely covered 99 extensively since they are difficult to measure and require large amounts of resources to 100 obtain sufficient and high quality data. However, emerging technologies such as LiDAR 101 (light detection and ranging) could potentially remedy this situation.

102 Airborne LiDAR records a three-dimensional set of points using laser ranging from an 103 aircraft or a drone (Lefsky et al. 2002). It captures data suitable to represent many of the 104 vegetation and landscape structural measures important to fungi (Vehmas et al. 2009, Lopatin 105 et al. 2016, Peura et al. 2016, Thers et al. 2017, Mao et al. 2018). As a relatively new 106 methodology, biodiversity studies that employ LiDAR have been limited in scope, typically 107 addressing only one taxonomic group or habitat type at the local scale, and strongly biased 108 towards forest ecosystems. However, studies using LiDAR-based indicators have already 109 been shown to explain up to $66 \%$ and $82 \%$ of local plant and fungi richness, respectively 110 (Lopatin et al. 2016, Peura et al. 2016, Thers et al. 2017). A recent study has demonstrated its 111 potential to provide spatially accurate and comprehensive measures by predicting the local 112 biodiversity of different taxonomic groups (plants, fungi, lichens, and bryophytes) across 113 multiple habitat types and large geographic extent (Moeslund et al. 2019). LiDAR may also 114 be a useful tool in studying dark diversity by incorporating potentially important 115 spatiotemporal dynamics such as succession and disturbance (Mokany and Shine 2003, Scott 116 et al. 2011, Pärtel et al. 2013). For example, recent studies have found that human impact 117 increases dark diversity in arbuscular mycorrhizal fungi (Pärtel et al. 2017a), that ruderal 118 plants are more likely to be in dark diversity (Moeslund et al. 2017), and that human density 119 and agricultural land-use influence dark diversity of vascular plants (Riibak et al. 2017).

120 Alongside these structural and environmental factors, fungal diversity depends on 121 biotic interactions, with a large proportion of fungi deriving their nutrients and carbon from 122 host plants (Tedersoo et al. 2014, Nguyen et al. 2016). Recent evidence has hinted on the 123 influence of these interactions on dark diversity, as plant species dependent on mycorrhiza 124 have been found to have greater dark diversity than those without these mutualist 125 relationships (Moeslund et al. 2017). Moreover, ectomycorrhizal fungal diversity seems to 126 increase exponentially with an increasing proportion of their host plants, suggesting that 127 competitive interactions among fungi might also drive their dark diversity (Pärtel et al. 128 2017b). Typical and strong species interactions are indeed typically considered in dark 
129 diversity, as the estimation hereof is usually based on species co-occurrences (Beals 1984,

130 McCune 1994, Münzbergová and Herben 2004, de Bello et al. 2012, Lewis et al. 2016).

131 However, this is usually done only within the species group being studied. For example, in

132 studies of plant dark diversity, only co-occurrences with other plants, and not fungi or other

133 species groups, are typically considered. However, recognizing the close and interconnected

134 relationship between plants and fungi allows for stronger and more realistic estimations of the

135 fungal dark diversity. Incorporating other taxonomic groups when determining species pools

136 and estimating dark diversity is not a new insight, and the importance of biotic interactions

137 across trophic groups has been discussed since the concept of dark diversity was first

138 introduced (Pärtel et al. 2011). Yet, such cross-species group data has never been included in

139 dark diversity estimates meaning that they may not sufficiently account for cross-species

140 group interactions, and this may be part of the explanation for why dark diversity is

141 sometimes over-estimated (Boussarie et al. 2018).

142 In this study, we examined a number of environmental factors influencing the local

143 dark diversity of fungi across habitat-types nationwide within Denmark. We used a

144 comprehensive biodiversity datasets covering major environmental gradients (Brunbjerg et

145 al. 2019) and combined it with LiDAR-based measurements. We also included fungi-plant-

146 co-occurrence information to estimate local fungal dark diversity and thereby acknowledge

147 the importance of their biotic interactions. More specifically, we addressed the following

148 questions: 1. To what degree can we explain local fungal dark diversity by abiotic and biotic

149 environmental factors? 2. Can vegetation and terrain structural factors that are important to

150 local fungal dark diversity be derived from LiDAR and if so, 3. how important are they

151 compared to field-measured factors?

\section{Methods}

\section{Study area and site selection}

154 The dataset was collected from a national biodiversity inventory in Denmark as part

155 of the "Biowide" research project (Brunbjerg et al. 2019). A total of 130 study sites $(40 \times 40$

$156 \mathrm{~m})$ were selected with a minimum distance of $500 \mathrm{~m}$ between each to reduce spatial 157 covariance with 30 sites allocated to cultivated habitats and 100 sites to natural habitats

158 (Figure 1). The cultivated subset was stratified according to the type of land use and the 159 natural subset was selected amongst uncultivated habitats and stratified according to 160 gradients in soil fertility, soil moisture, and successional stage. The "Biowide" project 
161 deliberately excluded saline and aquatic habitats but included temporarily inundated 162 depressions along with mires, bogs, and fens. The final set of 24 habitat strata consisted of 163 three types of fields (rotational, grass leys, set aside) and three types of plantations (beech, 164 oak, spruce), and the remaining 18 strata were natural or semi-natural habitats, constituting 165 all possible combinations of positions along three major natural environmental gradients: soil 166 fertility (rich, poor), soil moisture (dry, moist, wet), and successional stage (early, mid, late).

167 These 24 strata were replicated in five geographical regions in Denmark. The "Biowide" 168 dataset also includes a subset of 10 sites (two in each region) of hotspots for different 169 taxonomic groups in Denmark, which were selected by voting amongst active naturalists in 170 the Danish conservation and management societies. For further details on the design and data 171 collection procedures see Brunbjerg et al. (2019). 


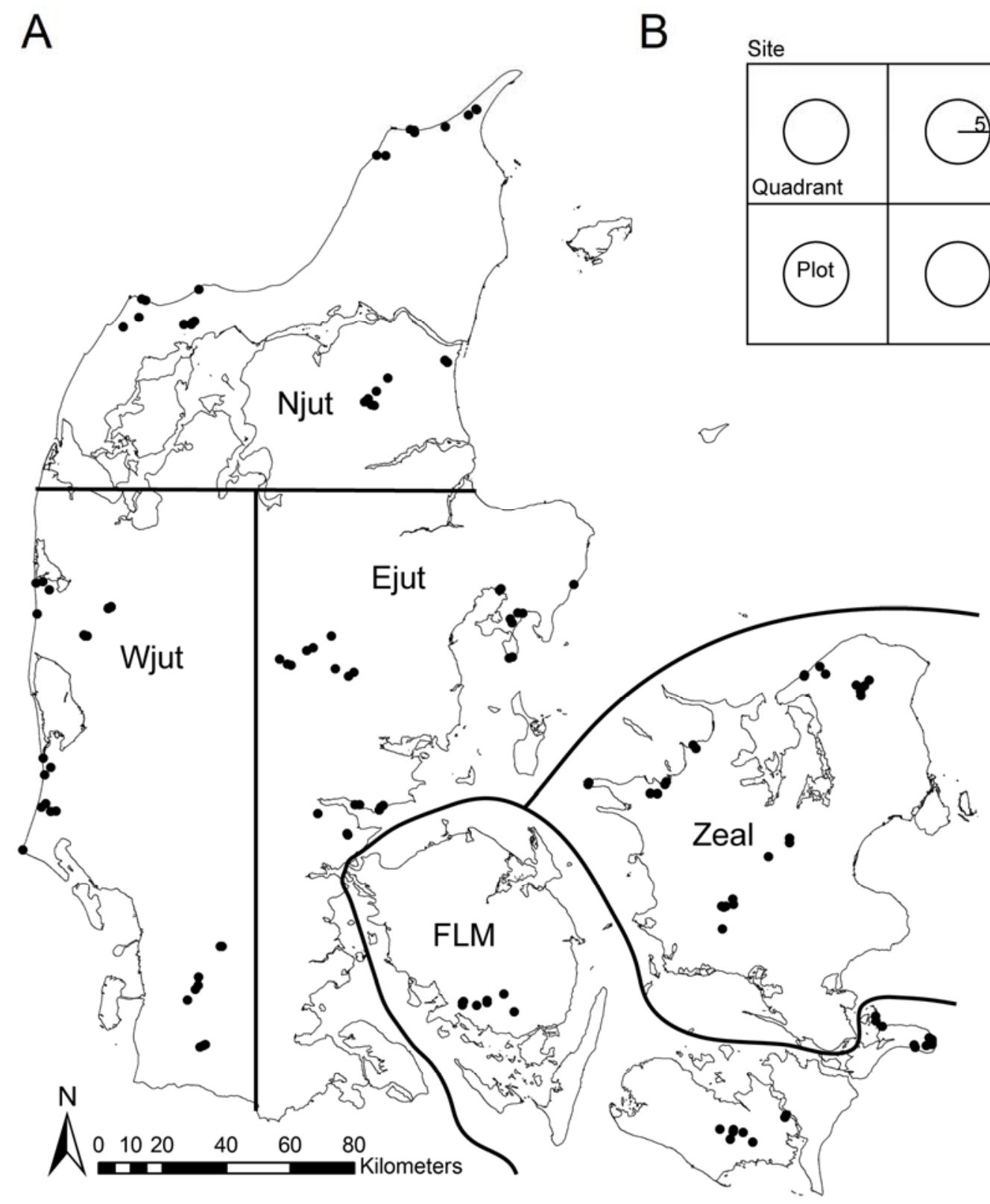

173 Figure 1. The (A) 130 selected study sites from a national biodiversity inventory and (B) the

174 four quadrants and 5 $\square \mathrm{m}$ circle plots within each site. Reprinted from Ejrnæs et al. (2018),

175 with permission from Elsevier.

\section{Field-measured variables}

We used fungi observational data from the "Biowide" field inventories (summarized

178 data and additional details in Brunbjerg et al. (2019)). Macro-fungal species were surveyed in 179 2014-2015 by an expert field-mycologist and volunteers during three inventories (up to one 
180 hour per site) in the main fruiting season (August - November) by actively searching

181 microhabitats and substrates (soil, herbaceous vegetation and debris, dead wood, litter, and

182 bark of trees up to $2 \mathrm{~m}$ ) within the $40 \times 40 \mathrm{~m}$ sites. Since truffles are difficult to find, we did

183 not consider these in this study. Subspecies and varieties were lumped to the species level.

184 After pre-processing, the dataset consisted of 6,269 observations of 1,017 species.

185 Vascular plant species observations were also taken from the "Biowide" database and 186 were originally inventoried by trained botanists during the summer 2014 and spring 2015 to 187 account for variations in phenology. We removed hybrids and neophytes (i.e. species that are 188 not considered a natural part of the vegetation given their history and dispersal ability, see 189 appendix tables 6-8 in Buchwald et al. (2013)) and lumped subspecies and varieties to the 190 species level. Species nomenclature for both plants and fungi follow the species checklist of 191 Denmark (allearter.dk).

192 Apart from the LiDAR-based measures (detailed below), we also considered field193 measured variables representing both abiotic conditions and available biotic resources known 194 to influence fungal diversity and communities (Table 1). For further details on data collection 195 and how the environmental field measurements were made see Brunbjerg et al. (2019). 
196 Table 1. Overview of the explanatory variables for fungal dark diversity models along with our hypothesized relationship with dark

197 diversity. If the standard deviation of a variable was calculated, in addition to its mean, the variable is denoted with an asterisk.

\begin{tabular}{ll}
\hline & Explanatory variables \\
\hline Field-based & Plant richness \\
measures & \\
& \\
& Litter (open habitats) and \\
& dead wood (forests)
\end{tabular}

dead wood (forests)

Soil $\mathrm{pH}$

Soil fertility index (SFI)

\begin{abstract}
Hypothesis
High plant richness could mean higher

community stability or reflect low human

impact. This would result in a lower dark

diversity

The more substrate represented by more organic matter gives more resources for fungi and hence

a lower dark diversity. Alternatively, organic

matter increases competition between fungi and

soil bacteria or causes many unfilled

microhabitats which would increase dark

diversity

Despite increasing importance of bacteria and

invertebrates in decomposition with increasing

soil $\mathrm{pH}$, we also expect less dominance and better opportunities for fungal colonization as

the base-rich soil environment is less restrictive,

where only few species can cope with low $\mathrm{pH}$

values, possibly resulting in a lower dark

diversity at high $\mathrm{pH}$
\end{abstract}

Asymmetric competition among vascular plants
References

(Kuiters 2013, Pellkofer et al.

2016, Yang et al. 2018)

2014)

(Clark 1997, Rousk et al. 2009,

Rousk et al. 2010)

(Buckland and Grime 2000, Liu et 
Soil moisture index (SMI)

Succession (Amplitude) increases with increasing soil fertility leading to loss of plant richness at high fertility levels and therefore potentially also increasing dark

\section{diversity}

Most fungi thrive at intermediate soil moisture levels, but have a rapid and opportunistic growth response to high moisture. Assuming

establishment is easier in intermediate moist environments dark diversity could be higher at high moisture. Alternatively, dark diversity could be high at intermediate moisture levels as this could yield many unfilled microhabitats

LiDAR-based Vegetation height*

measures

Taller vegetation could reflect encroachment by

shrubs and trees in open habitats and forests al. 2015, Nadeau and Sullivan

2015, Luo et al. 2017)

(Jacobson 1997, Kennedy and

Peay 2007)

(Zuo et al. 2016, Gómez et al.

resulting in more available microhabitats for

potential fungal species increasing their dark

diversity

Amplitude could reflect successional processes with later successional stages allowing fungi to become more established, resulting in lower dark diversity
(Fernández-Toirán et al. 2006,

Twieg et al. 2007, Hui et al. 2017) 


\section{Microtopography}

-Terrain roughness (SigmaZ)

-Terrain openness*

Light/heat

- Canopy openness (forests)*

-Heat load index*

-Solar irradiation*

-Vegetation cover*

Canopy complexity

-Echo ratio*
Microtopography increases availability of

microhabitats and hence could increase dark

diversity

Light availability increases fungal establishment success which would decrease dark diversity

Canopy complexity provides more niches directly in the canopy and could also be expected to be associated with a higher variation in the forest floor with small openings in the canopy and variation in tree ages. This could increase the number of unfilled microhabitats and hence the dark diversity
(Cantelmo Jr and Ehrenfeld 1999)

(Graham et al. 1982, Turner et al. 2009)

(Unterseher and Tal 2006, GómezHernández and Williams-Linera 2011, Dove and Keeton 2015) 
12

\section{LiDAR-based measures}

To enable the calculation of measures representing vegetation and terrain environmental and structural aspects, we used the latest nationally covering LiDAR-based point cloud for Denmark from the Danish Ministry of Environment. This dataset is freely available from www.kortforsyningen.dk and has a point density of 4-5 points $/ \mathrm{m}^{2}$. Originally, this dataset was recorded from fixed-wing airplanes at an altitude of approximately $680 \mathrm{~m}$ above ground level and a speed over ground of approximately $240 \mathrm{~km} / \mathrm{h}$. The data was recorded by Riegl LMS-680i scanners operating in the near-infrared wavelength $(1550 \mathrm{~nm})$ in a parallel line scan pattern during the springs and autumns of 2014 and 2015. For all calculations, we relied on the classification of points into ground, building and vegetation classes already present in the data set upon download.

To represent vegetation and terrain environmental and structural aspects, we calculated observed measures based on the point cloud data set. We calculated all measures at $1.5 \mathrm{~m}$ resolution (except for terrain roughness which was at $0.5 \mathrm{~m}$ resolution) and their means and standard deviations within $30 \mathrm{~m}$ radius circles centered in each study site. For all LiDAR processing and calculation, we used the OPALS tools (Pfeifer et al. 2014) version 2.3.1 in a Python 2.7 environment.

\section{Vegetation-related measures}

To represent succession and to some degree moisture balance in both vegetation and soil, we used the amplitude of each echo representing a point in the LiDAR point cloud. This amplitude is high if the reflecting surface is flat (i.e., smooth) and with high reflectivity. It is low when the light energy is distributed between several returns for example in tree canopies, or when surfaces have low reflectivity, are complex, or translucent (e.g., leaves). The wavelength used to record the point cloud data is sensitive to leaf water content (Junttila et al. 2018) and soil moisture (Zlinszky et al. 2014). Since the amplitude depends on reflectivity, which varies across months and aircraft types (slightly different flying heights) used for data recording, the amplitude was corrected to account for these biases. We constructed a Generalized Linear Model (GLM) with Gaussian link having the raw amplitude as response and flight month as well as aircraft type as explanatory factors and used only the residuals of this model for input in our statistical modelling. We also tried using flight year as an explanatory factor, but this did not improve the 
model $(\triangle \mathrm{AIC}<2)$. These residuals will be referred to as the corrected amplitude in the following. Unfortunately, we did not have reference data enabling a full calibration of this measure (Höfle and Pfeifer 2007).

To represent vegetation height, we estimated this measure by subtracting the terrain model from the surface model (two raster files, detailed in the following). The terrain model (DTM) calculation details are given in the section on "Terrain-structure measure". The surface model was calculated using the DSM module in OPALS using all vegetation and ground points.

To reflect the penetrability and succession of the vegetation we calculated the echo ratio (Höfle et al. 2012). Echo ratio is high where the surface is impenetrable and relatively smooth and lower where the surface is uneven or penetrable. In order to calculate the echo ratio, estimating normals for each point is required. We did this using the Normals module in OPALS with a robust plane fit based on the 12 nearest neighboring points. Subsequently, we calculated the echo ratio for each terrain and vegetation point using a search radius of $1.5 \mathrm{~m}$ along with the slope adaptive method implemented in the EchoRatio module of OPALS.

To estimate light conditions, we calculated the canopy openness for all points categorized

243 as "ground", but contrary to terrain openness (see below), we calculated this considering 244 vegetation points as well. Therefore, canopy openness represents the actual blocking of the sky 245 view by the canopy around each ground point. Canopy openness is high for ground points inside canopy gaps and low for ground points beneath a closed canopy.

Lastly, as an estimate of vegetation cover, we calculated the fraction of vegetation points

248 to all points (excluding unclassified points and those representing buildings and noise). This 249 measure will be high if the vegetation is dense or the cover of vegetation is relatively high, and 250 low for areas with no vegetation.

\section{$\underline{\text { Terrain-structure measures }}$}

To enable the calculation of several terrain-related measures, we calculated a digital 253 terrain model (DTM) for each study site representing the elevation above sea level. To do this we 254 used the DTM module of OPALS based on only ground points. We set the module to use 8 255 neighboring points and a search radius of $6 \mathrm{~m}$. To represent key features of the local terrain (e.g., 
aspect (used for heat load index calculation, see below). For this task, we used the GridFeature

258 module of OPALS using the DTM as input, a kernel size of 1 and requesting the terrain slope 259 and aspect (slope direction) in radians.

To reflect local heat input, we calculated the heat load index based on the terrain aspect 261 following the heat load index formula in McCune and Keon (2002). This index reaches 262 maximum values on southwest-facing slopes and zero on northeast-facing slopes. We also 263 calculated the potential solar irradiation based on terrain slope, aspect, and latitude following 264 equation 3 in McCune and Keon (2002).

To estimate micro-scale terrain heterogeneity, we calculated the terrain roughness 266 (SigmaZ) using only ground points as input. This measure represents the standard deviation of 267 the interpolated grid height. The OPALS DTM module outputs this measure as a by-product 268 when constructing a DTM. However, unlike the rest of the LiDAR measures in this study, the 269 terrain roughness was calculated at $0.5 \times 0.5 \mathrm{~m}$ resolution mirroring micro-scale terrain 270 variations.

271 To represent site-scale terrain heterogeneity, we calculated the terrain openness (Doneus 272 2013). Terrain openness is defined as the opening angle of a cone (having the radius of the 273 kernel) turned upside down - with its tip restrained to the point of interest - that touches the 274 terrain surface. To calculate this, we used the PointStats module of OPALS requesting "positive 275 openness" based on only ground points and a search radius of $5 \mathrm{~m}$. This measure is high in flat 276 (relative to the scale at which it is calculated) areas and low in heterogeneous terrains.

277 Finally, to test the importance of variability in the LiDAR measures we calculated the 278 standard deviation for LiDAR measures for which we believed it made ecological sense (Table 279 1).

280 Data analysis

281 Data preparation

282 Prior to statistical analysis, we removed the six intensively managed fields from the study 283 sites, as these were ploughed fields. We also removed two study sites because they were flooded 284 during the LiDAR data recording period. Finally, we removed one site due to an extreme outlier 
285 in the LiDAR amplitude values (300 vs. a range of values between 10 and 130). Our final dataset 286 therefore comprised a total of 121 study sites.

Our initial visual inspection of the data revealed that many of the LiDAR measures were relevant only for woodlands and therefore strongly zero-inflated in the open landscapes. The analyses in this study were therefore separately run for open habitats and woodlands. Open

290 habitats included grasslands, fens, bogs, and other habitats with only few sporadic occurrences of 291 trees. The woodlands dataset consisted of forests, thickets and shrubland (e.g. willow).

293 variables for statistical modelling as explanatory factors. Obviously, a number of these variables 294 were strongly inter-correlated (Appendix 1). For example, echo ratio was strongly related to 295 canopy and light measures (Appendix 1). Therefore, we selected only those variables that we 296 hypothesized to affect local fungal dark diversity (See Table 1). Subsequently, to avoid issues 297 with multi-collinearity we calculated Variance Inflation Factors (VIFs) causing us to remove 298 vegetation height as an explanatory factor for the open landscapes to ensure VIF values below 10 299 following Kutner et al. (2005). Subsequently, the maximum VIF value of explanatory factors 300 used together in the same models was 4.8 and 5.7 for woodlands and open habitats respectively. 301 We scaled all explanatory variables to a mean of zero and a standard deviation of one. To strive 302 for normal distribution of explanatory variables we log- or square-root transformed those where 303 this made obvious distributional improvements based on visual examination of the histograms. 
Appendix 1. Correlation plot between environmental and LiDAR variables. All significant interactions are colored red for negative relationships and blue for positive relationships, with the size and darkness of the color representing the strength of the relationship. Non-significant correlations are blank.



Dark diversity

All statistical analyses mentioned in the following were performed in $\mathrm{R}$ version 3.5.3 ( $\mathrm{R}$

313 Core Team 2019). To calculate the dark diversity for each site, we first calculated the site-

314 specific species pool using the Beals' index (Beals 1984), as recommended by Lewis et al. 
315 (2016), using the 'beals' function in the 'vegan' package (Oksanen et al. 2017). The Beals' index

316 represents the probability that a particular species will occur within a given site based on the

317 assemblage of co-occurring species (Beals 1984, McCune 1994, Münzbergová and Herben

318 2004). The threshold used for including a particular species in the site-specific species pool was

319 the $5^{\text {th }}$ percentile of the Beals' index value for each species (Gijbels et al. 2012, Ronk et al.

320 2015). Preceding the calculation of each threshold, the lowest Beals' index value among plots

321 with the occurrence of the species in question was identified, and all plots having values below

322 the minimum were not considered. We calculated two measures of the site-specific species pool

323 for each site: (1) using only fungi co-occurrence and (2) co-occurrences of both observed fungi

324 and vascular plants at each site to acknowledge the fungal-plant linkages (i.e., both fungi and

325 plant species were in the presence/absence matrix used to calculate Beals' index). Dark diversity

326 was calculated by subtracting observed fungal species richness from the site-specific species

327 pool. Since site-specific species pools differ between sites, we calculated the relative dark

328 diversity for each site as dark diversity (species predicted from the site-specific species pool but

329 not observed) divided by the regional pool to enable comparison of results across habitats.

$\underline{\text { Statistical analysis }}$

331 To investigate what characterizes sites with a high fungal dark diversity we constructed

332 GLMs with a Gaussian link having the estimated relative dark diversity (described above) as the

333 response variable. We constructed models for both open habitats and woodlands, and for both

334 dark diversity estimates (see the section on dark diversity). Initially, we fitted models using only

335 the LiDAR measures as explanatory factors, to test the degree to which fungal dark diversity

336 patterns could be explained using LiDAR data alone. Subsequently, we fitted a similar model

337 with both measured and LiDAR variables as explanatory factors (Table 1), giving insight into

338 how much more explanatory power one gains by using measured variables in addition to LiDAR.

339 To allow for non-linear relationships for variables corresponding to the intermediate disturbance

340 hypothesis (Connell 1978, Townsend et al. 1997) and intermediate productivity hypothesis

341 (Fraser et al. 2015), we used Akaike's Information Criterion (AIC) (Burnham and Anderson

342 2002) to evaluate if inclusion of squared terms for the variables SMI, SFI, light, soil pH, and

343 bare soil (see Table 1) improved the model fit. If so, we kept the squared term of the variable in

344 question instead of the linear effect. After the initial fit and checking for non-linearity as 
345 described above, we ran a backward model selection procedure for each model based on AIC.

346 The procedure stopped when AIC did not drop anymore and $\triangle$ AIC was above 2 (Burnham and

347 Anderson 2002). In each iteration, we dropped the variable causing the smallest change in AIC

348 value. As a final step, we checked model residuals to ensure that these were normally distributed.

349 We did not conduct spatial modelling in this study, since the original field-work design lying

350 behind the data was designed to avoid spatial autocorrelation, and tests for all the species groups

351 originally inventoried concluded that spatial signals were of minor to little importance (see

352 Brunbjerg et al. (2019), and also "Study area and site selection").

353 Results

354 The two relative fungal dark diversity estimates (based on fungi-only and both fungi- and 355 plant co-occurrences) were between $0.17-0.93$ (open habitats, median 0.51) and $0.20-0.63$ 356 (woodland, median: 0.39); and 0.21 - 0.95 (open habitats, median: 0.56) and $0.24-0.7$ 357 (woodland, median: 0.44) respectively. In most cases, our models explained between 20-30\% of 358 the variation in fungal dark diversity and more than $40 \%$ for the woodlands models when 359 including both LiDAR and measured variables (Table 2). In the "fungi-only dark diversity" 360 model for woodland habitats (Table 2) the squared term of soil pH did improve model fit, but 361 this term was left out during the subsequent model selection procedure.

The only LiDAR variable significant in both open habitats and woodlands was amplitude, which was significant in all models for woodlands and in LiDAR-only models for open habitats

364 (Table 2). This variable had a positive effect on dark diversity in woodlands (Table 2) but a 365 negative influence in open habitats (Table 2). Echo ratio was the only other significant LiDAR 366 variable in our analyses and positively influenced dark diversity in open habitats (Table 2). Plant 367 richness was negatively related to local fungal dark diversity and had the strongest impact of all 368 the field-measured factors included in our analyses (Table 2). Also, soil fertility and moisture were positively correlated with fungal dark diversity in open habitats (Table 2).

In all cases, models considering only the structural environment (LiDAR only) were outperformed by models considering plant richness and the abiotic environment in addition to

372 the structural, notably in the open habitats (Table 2). Appendix 1 shows all pair-wise Spearman 373 correlations between the explanatory variables used and Appendix 2 shows observed fungi 374 richness against the two dark diversity measures for both open and woodland habitats. 
376 Table 2. Modelling coefficients for the best models (i.e. after model selection) regressing dark diversity estimates based on only fungi

377 co-occurrences (Fungi-only dark diversity) or based on both fungi and plant co-occurrences (Fungi-plant dark diversity) against the

378 selected explanatory variables. Significant variables were from either a LiDAR-only or a full model with both LiDAR-based and field-

379 measured predictors.

\begin{tabular}{|c|c|c|c|c|c|c|c|c|}
\hline & & & \multirow{2}{*}{$\mathrm{R}^{2}$} & \multicolumn{2}{|c|}{ LiDAR variables } & \multicolumn{3}{|c|}{ Field-measured variables } \\
\hline & & & & Amplitude & $\begin{array}{l}\text { Echo } \\
\text { ratio }\end{array}$ & Plant richness & Soil fertility & $\begin{array}{l}\text { Soil } \\
\text { moisture }\end{array}$ \\
\hline \multirow{4}{*}{$\begin{array}{l}\text { Woodland } \\
\text { habitats }\end{array}$} & Fungi-only & Lidar-only model & 0.24 & 0.03 & - & & - & - \\
\hline & & Full model & 0.40 & 0.04 & - & -0.05 & - & - \\
\hline & $\begin{array}{l}\text { Fungi-plant } \\
\text { dark diversity }\end{array}$ & Lidar-only model & 0.23 & 0.03 & - & & - & - \\
\hline & & Full model & 0.44 & 0.04 & - & -0.05 & - & - \\
\hline \multirow[t]{4}{*}{$\begin{array}{l}\text { Open } \\
\text { habitats }\end{array}$} & $\begin{array}{l}\text { Fungi-only } \\
\text { dark diversity }\end{array}$ & Lidar-only model & 0.10 & -0.05 & 0.01 & & - & - \\
\hline & & Full model & 0.30 & - & 0.01 & -0.08 & 0.06 & 0.04 \\
\hline & $\begin{array}{l}\text { Fungi-plant } \\
\text { dark diversity }\end{array}$ & Lidar-only model & 0.07 & -0.04 & 0.01 & & - & - \\
\hline & & Full model & 0.34 & - & 0.01 & -0.10 & 0.06 & - \\
\hline
\end{tabular}


Appendix 2. Relationship between observed fungal diversity and dark diversity estimates in woodland based on (A) only fungi co-occurrences (Fungi-only dark diversity) or (B) fungi and plant co-occurrences (Fungi-plant dark diversity), and in open habitats based on (C) only fungi 383 co-occurrences (Fungi-only dark diversity) or (D) fungi and plant co-occurrences (Fungi-plant
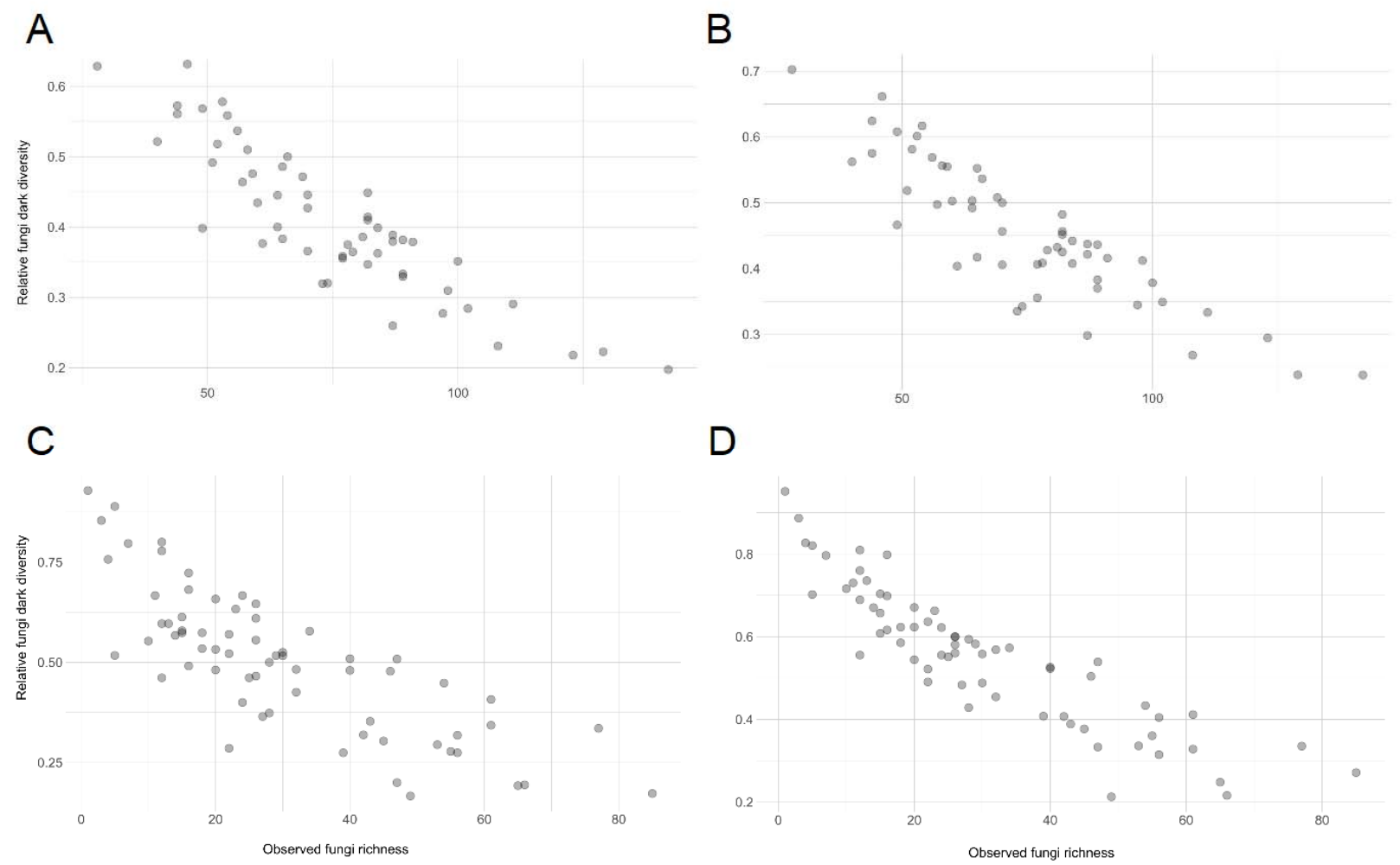

\section{Discussion}

In this study, we demonstrate for the first time that LiDAR derived variables, alone and in combination with field-measured variables, can explain a significant amount of the variation in local dark diversity of temperate macro-fungal communities. Our findings indicate that the 390 dark diversity of fungi is influenced by the local vegetation structure, plant associations, and the 391 abiotic environment. This is not surprising since local observed fungal diversity is also 392 determined by these factors to a large degree (Thers et al. 2017, Yang et al. 2017, Moeslund et 393 al. 2019). Indeed, the relative dark diversity analyzed in this study correlated with the observed 394 fungal species richness (Appendix 2), which was expected given that the dark diversity 395 calculations are based on the species present (Noreika et al. 2020). On the other hand, there are 
differences between these two measures, so the results presented here are not necessarily applicable to the observed fungal diversity. We also find that models including field-based variables explained the dark diversity of fungi far better than models relying solely on LiDAR, notably in open landscapes. While LiDAR has the advantage that one can record data from huge areas in very fine detail for relatively low cost, our results indicates that to get the best explanation of local fungal diversity patterns fieldwork is still needed.

\section{LiDAR-based measures}

This study shows that LiDAR captures habitat characteristics potentially important for

404 fungal dark diversity which are not represented by traditional field-measured variables. Notably, 405 the relationship between fungal dark diversity and LiDAR-derived vegetation structure in 406 woodlands was relatively strong. Although LiDAR can successfully quantify biophysical 407 characteristics in all types of habitats, it is known to be more effective in forested habitats (Su 408 and Bork 2007), supporting these findings. The most important LiDAR variables for modelling 409 fungal dark diversity were amplitude and echo ratio which gives us important insights into what 410 environmental aspects, which are not typically recorded in field-surveys, can be captured by a 411 LiDAR approach.

412 The LiDAR measure of amplitude is sensitive both to surface reflectivity and to the 413 number of targets hit by the laser pulse (Moeslund et al. 2019). The lower the reflectivity and the 414 more targets between which the light energy is distributed, the lower the amplitude associated 415 with a given point. This would result in high amplitudes in flatter surfaces while yielding low 416 amplitudes in tall and more complex canopies, or translucent surfaces such as leaves. Hence, this 417 variable can be a proxy for succession stage, surface evenness, or vegetation density; since both 418 flat and sparsely vegetated as well as densely vegetated canopies preventing light penetration 419 will yield high amplitude. Supporting this, amplitude was positively correlated with vegetation 420 height and vegetation cover (denser vegetation resulted in higher amplitude) and negatively 421 correlated with echo ratio (vegetation complexity, see below) and canopy openness. In 422 woodlands, the dark diversity of fungi was positively related to amplitude, suggesting that more 423 species are missing in the relatively tall and dense forests compared to more complex woodlands 424 (e.g., with canopy openings). The positive association between LiDAR amplitude and dark 425 diversity could therefore be a consequence of communities in older well-developed shrubland or 
426 old-growth forests with windthrows or other openings, having allowed fungi more time to

427 become established with their associated plants (Fernández-Toirán et al. 2006, Twieg et al.

428 2007). Indeed, among the top half of woodland plots with regards to amplitude were plantations

429 (which often have dense canopy and equal-aged trees) and most of them contained high relative

430 fungal dark diversity, while the bottom half of the plots, those having the lowest amplitude and

431 dark diversity, were mostly old forests or shrublands with a more well-developed vegetation

432 structure (e.g., dead or fallen wood, or complex sub-canopy layer).

433 In open habitats, amplitude and echo-ratio were negatively and positively related to

434 fungal dark diversity, respectively. These results indicate that fewer species are missing from the

435 more even early-successional grasslands without trees and shrubs. We suggest this could be the

436 result of encroachment due to the widespread abandonment of ancient grassland management

437 practices resulting in a loss of small-statured typical grassland plant species without a

438 corresponding gain in species associated with scrub and woodland. It could also reflect that

439 fewer species are missing from calcareous or sandy grasslands since open limestone and white

440 sand have a relatively high reflectivity.

\section{$441 \quad$ Plant richness}

442 The most important field-measured variable for modelling fungal dark diversity was plant 443 species richness which was negatively related to dark diversity in both open habitats and 444 woodlands. Plant richness and composition are well-known to correlate with fungal richness and 445 composition (Zak et al. 2003, Chen et al. 2017, Yang et al. 2017, Brunbjerg et al. 2018, Wang et 446 al. 2018), and sites with lower plant species richness have previously been found to have a 447 relatively higher proportion of plants in the dark diversity (Fløjgaard et al. 2020). Here, the 448 negative relation between plant richness and fungal dark diversity may be attributed to greater 449 plant richness frequently associated with more stable communities and ecosystems (Kuiters 450 2013, Pellkofer et al. 2016, Yang et al. 2018), which could indicate longer continuity and hence 451 time for fungi to establish. Alternatively, host specific fungi species could be missing due to 452 absence of their symbiotic plant species (Dickie 2007). However, in our study, plant richness had 453 almost the same effect on both fungal dark diversity accounting for present plant species and 454 where these presences where unaccounted for. This points to plant hosts playing a minor role for 455 fungal dark diversity, which is unsurprising as it likely indicates that the calculation of fungal 
dark diversity using the Beals' index does not allow fungi having non-present hosts into the site-

457 specific species pool. Another possible explanation is that plant richness mirrors human impact.

458 Generally plant species richness have declined over several decades and continue to as a 459 consequence of agricultural intensification and abandonment of extensive land-use (Hülber et al. 460 2017). Other studies have found human disturbance to be strongly related to fungal richness and 461 dark diversity patterns (Epp Schmidt et al. 2017, Pärtel et al. 2017a), and future studies may help 462 to tease apart these effects.

\section{Abiotic environment}

Soil fertility is often associated with fungal diversity (Balser et al. 2005, Kalliokoski et al. 2010, Sterkenburg et al. 2015) and was found to have a positive relationship with dark diversity in open habitats. In general, soil fertility influences plant species richness negatively 467 through asymmetric competition (Buckland and Grime 2000, Dybzinski et al. 2008, Nadeau and 468 Sullivan 2015, Luo et al. 2017). This could explain the negative relationship between the local 469 dark diversity of fungi and soil fertility: lower plant species richness yields a higher dark 470 diversity (see discussion above on "Plant richness"). However, the effect might also be 471 uncoupled from plants and simply due to changes in the soil decomposition microbiota from 472 fungal to bacterial dominance along a gradient of soil fertility and $\mathrm{pH}$ (Blagodatskaya and 473 Anderson 1998). Another alternative explanation is that soil fertility affects the density of soil 474 mycophagous and microarthropod species (Cole et al. 2005) which also may affect fungal dark 475 diversity (Crowther et al. 2013). However, while this explanation might be plausible, the 476 underlying mechanisms are largely unknown, calling for further research to dissect the 477 interactions between soil fertility, soil microarthropods and fungal diversity.

We also found soil moisture had a positive relationship with fungal dark diversity in open 479 habitats. Moisture is known to influence fungal communities (Gómez-Hernández and Williams480 Linera 2011, Gupta et al. 2018, Frøslev et al. 2019) as it affects the growth, colonization rate, 481 and spore and fruit body production (Salusso and Moraña 1995, Jacobson 1997, Kennedy and 482 Peay 2007). The relationship between fungi and plants is probably important in this regard 483 because soil moisture causes a high turnover in plant species composition (e.g., Moeslund et al. 484 (2013), and in turn, affects the quality and availability of resources for below-ground fungal 
excluding most macro-fungi species from the wet habitats (Heilmann-Clausen et al. 2019). This

487 filter may also be the main reason for the higher fungal dark diversity found in the wet habitats

488 when plant co-occurrences was not included in determining the site-specific species pool. On the 489 other hand, the interdependencies between fungi and plants, and the strong link between plant 490 communities and soil moisture gradients (Xiong et al. 2003, Silvertown et al. 2015, Valdez et al. 491 2019), may explain why soil moisture was not significant in models where plant co-occurrences 492 was included in determining the site-specific species pool, as this approach perhaps accounts for 493 these interactions.

\section{Uncertainties}

495 One drawback of basing a study on an organism group like fungi, which live a mostly 496 hidden life, is the unavoidable issues concerning overlooked species and hidden diversity in 497 general (Milberg et al. 2008, Abrego et al. 2016). If such errors are biased towards specific plots 498 our results could be affected. However, the field-work behind the dataset used here was planned 499 to avoid this exact issue by including several visits at each site at different times of the year, and 500 we do not believe this confounds our findings. Nevertheless, there is always uncertainty when 501 estimating unknowns, such as which species are actually absent despite the fact that they could 502 indeed be in a given site. In this study we used on of the most comprehensive and best possible 503 data set along with state-of-the-art methods to calculate these estimates (see e.g. (Lewis et al. 504 2016, Moeslund et al. 2017), and we therefore believe our results are indeed sound and realistic 505 despite this uncertainty.

\section{Conclusion}

This is the first study to investigate potential drivers of the local dark diversity of fungi using both LiDAR derived vegetation and terrain structure as well as field-measured variables. We showed that local fungal dark diversity is strongly dependent on the environment with

511 knowledge, this is the first study using cross-species group co-occurrence data to determine 512 species pools. This may be a more ecologically sound methodology than using only one taxon 513 group, especially for interdependent taxonomic groups. Future studies and novel approaches will 514 be required to unravel the causal links between fungal communities and habitat and vegetation 515 characteristics; and to gain a better understanding of how LIDAR-based measures can be 
516 interpreted as measures of vegetation and terrain structure. Using LiDAR as a tool to determine

517 dark diversity, in conjunction with ecological field measurements, may provide a valuable tool to

518 better guide conservation and restoration planning by identifying sites with high restoration

519 potential (high dark diversity) and high priority for conservation (low dark diversity, or sites

520 where the fungal communities are more "complete").

\section{Acknowledgements}

522 We thank Thomas Læssøe for collecting and identifying macro-fungi. We sincerely thank Aage

523 V. Jensen Nature Fund for financial support to CF, AKB, JM, LD, KC and JV through the

524 project “Dark Diversity in Nature Management". The Biowide project and REJ was supported by

525 a grant from the Villum Foundation (VKR-023343). MP has been supported by the Estonian

526 Ministry of Education and Research (IUT20-29), and the European Regional Development Fund

527 (Centre of Excellence EcolChange). The authors declare no conflict of interest.

\section{$528 \quad$ Literature Cited}

Abrego, N., Halme, P., Purhonen, J. and Ovaskainen, O. (2016) 'Fruit body based inventories in wood-inhabiting fungi: Should we replicate in space or time?', Fungal Ecology, 20, 225232.

Averill, C., Turner, B. L. and Finzi, A. C. (2014) 'Mycorrhiza-mediated competition between plants and decomposers drives soil carbon storage', Nature, 505(7484), 543-545.

Balser, T. C., Treseder, K. K. and Ekenler, M. (2005) 'Using lipid analysis and hyphal length to quantify AM and saprotrophic fungal abundance along a soil chronosequence', Soil Biology and Biochemistry, 37(3), 601-604.

Beals, E. W. (1984) 'Bray-Curtis ordination: An effective strategy for analysis of multivariate ecological data' in MacFadyen, A. and Ford, E. D., eds., Advances in Ecological ResearchAcademic Press, 1-55. on the fungal-to-bacterial ratio and qCO2 of microbial communities in forest soils', Soil 
Boussarie, G., Bakker, J., Wangensteen, O. S., Mariani, S., Bonnin, L., Juhel, J.-B., Kiszka, J. J., Kulbicki, M., Manel, S. and Robbins, W. D. (2018) 'Environmental DNA illuminates the dark diversity of sharks', Science advances, 4(5), eaap9661.

Brunbjerg, A. K., Bruun, H. H., Broendum, L., Classen, A. T., Fog, K., Froeslev, T. G., Goldberg, I., Hansen, M. D. D., Hoeye, T. T., Laessoee, T., Newman, G., Skipper, L., Soechting, U. and Ejrnaes, R. (2019) 'A systematic survey of regional multitaxon biodiversity: evaluating strategies and coverage', BMC Ecology, 19(43), 158030.

Buchwald, E., Wind, P., Bruun, H. H., Møller, P. F., Ejrnæs, R. and Svart, H. E. (2013) 'Hvilke planter er hjemmehørende i Danmark?', Flora \& Fauna, 118, 73-96.

Buckland, S. M. and Grime, J. P. (2000) 'The effects of trophic structure and soil fertility on the assembly of plant communities: a microcosm experiment', Oikos, 91(2), 336-352.

Burnham, K. P. and Anderson, D. R. (2002) Model Selection and Multi-model Inference: A Practical Information-Theoretic Approach, New York: Springer.

Cantelmo Jr, A. J. and Ehrenfeld, J. G. (1999) 'Effects of microtopography on mycorrhizal infection in Atlantic white cedar (Chamaecyparis thyoides (L.) Mills.)', Mycorrhiza, 8(4), 175-180.

Chen, Y.-L., Xu, T.-L., Veresoglou, S. D., Hu, H.-W., Hao, Z.-P., Hu, Y.-J., Liu, L., Deng, Y., Rillig, M. C. and Chen, B.-D. (2017) 'Plant diversity represents the prevalent determinant of soil fungal community structure across temperate grasslands in northern China', Soil Biology and Biochemistry, 110, 12-21. and host plant growth and mineral acquisition at low pH', Plant and Soil, 192(1), 15-22. 
Cole, L., Buckland, S. M. and Bardgett, R. D. (2005) 'Relating microarthropod community structure and diversity to soil fertility manipulations in temperate grassland', Soil Biology and Biochemistry, 37(9), 1707-1717.

Connell, J. H. (1978) 'Diversity in tropical rain forests and coral reefs', Science, 199(4335),

Cornell, H. V. and Harrison, S. P. (2014) 'What are species pools and when are they important?', Annual Review of Ecology, Evolution, and Systematics, 45(1), 45-67.

Crowther, T. W., Stanton, D. W., Thomas, S. M., A'Bear, A. D., Hiscox, J., Jones, T. H., Voříšková, J., Baldrian, P. and Boddy, L. (2013) 'Top $\square$ down control of soil fungal community composition by a globally distributed keystone consumer', Ecology, 94(11), 2518-2528.

de Bello, F., Price, J. N., Münkemüller, T., Liira, J., Zobel, M., Thuiller, W., Gerhold, P., Götzenberger, L., Lavergne, S. and Lepš, J. (2012) 'Functional species pool framework to test for biotic effects on community assembly', Ecology, 93(10), 2263-2273.

Dickie, I. A. (2007) 'Host preference, niches and fungal diversity', The New Phytologist, 174(2), 230-233.

Doneus, M. (2013) 'Openness as visualization technique for interpretative mapping of airborne

Dove, N. C. and Keeton, W. S. (2015) 'Structural Complexity Enhancement increases fungal species richness in northern hardwood forests', Fungal Ecology, 13, 181-192. increases with plant species diversity in a long-term biodiversity experiment', Oecologia, 158(1), 85-93. A. J. and Bruun, H. H. (2018) 'Uniquity: A general metric for biotic uniqueness of sites', Biological Conservation, 225, 98-105. 
Epp Schmidt, D. J., Pouyat, R., Szlavecz, K., Setälä, H., Kotze, D. J., Yesilonis, I., Cilliers, S., Hornung, E., Dombos, M. and Yarwood, S. A. (2017) 'Urbanization erodes ectomycorrhizal fungal diversity and may cause microbial communities to converge', Nature ecology \& evolution, 1, 0123.

Fraser, L. H., Pither, J., Jentsch, A., Sternberg, M., Zobel, M., Askarizadeh, D., Bartha, S., Beierkuhnlein, C., Bennett, J. A. and Bittel, A. (2015) 'Worldwide evidence of a unimodal relationship between productivity and plant species richness', Science, 349(6245), 302-305.

Frøslev, T. G., Kjøller, R., Bruun, H. H., Ejrnæs, R., Hansen, A. J., Læssøe, T. and HeilmannClausen, J. (2019) 'Man against machine: Do fungal fruitbodies and eDNA give similar biodiversity assessments across broad environmental gradients?', Biological Conservation, 233, 201-212.

Geml, J., Gravendeel, B., van der Gaag, K. J., Neilen, M., Lammers, Y., Raes, N., Semenova, T. A., de Knijff, P. and Noordeloos, M. E. (2014) 'The Contribution of DNA Metabarcoding to Fungal Conservation: Diversity Assessment, Habitat Partitioning and Mapping RedListed Fungi in Protected Coastal Salix repens Communities in the Netherlands', PLOS ONE, 9(6), e99852.

Gijbels, P., Adriaens, D. and Honnay, O. (2012) 'An orchid colonization credit in restored calcareous grasslands', Écoscience, 19(1), 21-28.

Gómez-Hernández, M. and Williams-Linera, G. (2011) 'Diversity of macromycetes determined by tree species, vegetation structure, and microenvironment in tropical cloud forests in Veracruz, Mexico', Botany, 89(3), 203-216.

Gómez, F. J. R., Navarro-Cerrillo, R. M., Pérez-de-Luque, A., Oßwald, W., Vannini, A. and Morales-Rodríguez, C. (2019) 'Assessment of functional and structural changes of soil fungal and oomycete communities in holm oak declined dehesas through metabarcoding analysis', Scientific reports, 9(1), 5315. 
Graham, J. H., Leonard, R. T. and Menge, J. A. (1982) 'Interaction of light intensity and soil temperature with phosphorus inhibition of vesicular-arbuscular mycorrhiza formation', New Phytologist, 91(4), 683-690.

Gupta, M. M., Gupta, A. and Kumar, P. (2018) 'Urbanization and biodiversity of arbuscular mycorrhizal fungi: The case study of Delhi, India', Revista de Biología Tropical, 66(4), 1547-1558.

Heilmann-Clausen, J., Frøslev, T. G., Læssøe, T. and Petersen, J. H. (2019) Danmarks svampeatlas 2009-2013, Svampetryk.

Höfle, B., Hollaus, M. and Hagenauer, J. (2012) 'Urban vegetation detection using radiometrically calibrated small-footprint full-waveform airborne LiDAR data', ISPRS Journal of photogrammetry and remote sensing, 67, 134-147.

Hubbell, S. P. (2011) The unified neutral theory of biodiversity and biogeography (MPB-32),

Höfle, B. and Pfeifer, N. (2007) 'Correction of laser scanning intensity data: Data and modeldriven approaches', ISPRS Journal of photogrammetry and remote sensing, 62(6), 415433.

Hui, N., Liu, X., Kotze, D. J., Jumpponen, A., Francini, G. and Setälä, H. (2017) 'Ectomycorrhizal Fungal Communities in Urban Parks Are Similar to Those in Natural Forests but Shaped by Vegetation and Park Age', Applied and Environmental Microbiology, 83(23), e01797-17.

Hülber, K., Moser, D., Sauberer, N., Maas, B., Staudinger, M., Grass, V., Wrbka, T. and Willner, W. (2017) 'Plant species richness decreased in semi-natural grasslands in the Biosphere Reserve Wienerwald, Austria, over the past two decades, despite agri-environmental measures', Agriculture, ecosystems \& environment, 243, 10-18.

Humphrey, J. W., Newton, A. C., Peace, A. J. and Holden, E. (2000) 'The importance of conifer plantations in northern Britain as a habitat for native fungi', Biological Conservation, 96(2), 241-252.

Jacobson, K. M. (1997) 'Moisture and substrate stability determine VA-mycorrhizal fungal community distribution and structure in an arid grassland', Journal of Arid Environments, $35(1), 59-75$. 
Junttila, S., Sugano, J., Vastaranta, M., Linnakoski, R., Kaartinen, H., Kukko, A., Holopainen, M., Hyyppä, H. and Hyyppä, J. (2018) 'Can leaf water content be estimated using multispectral terrestrial laser scanning? A case study with Norway spruce seedlings', Frontiers in plant science, 9, 299.

Kalliokoski, T., Pennanen, T., Nygren, P., Sievänen, R. and Helmisaari, H.-S. (2010) 'Belowground interspecific competition in mixed boreal forests: fine root and ectomycorrhiza characteristics along stand developmental stage and soil fertility gradients', Plant and Soil, 330(1-2), 73-89.

Kennedy, P. G. and Peay, K. G. (2007) 'Different soil moisture conditions change the outcome of the ectomycorrhizal symbiosis between Rhizopogon species and Pinus muricata', Plant and Soil, 291(1), 155.

Kivlin, S. N., Hawkes, C. V. and Treseder, K. K. (2011) 'Global diversity and distribution of arbuscular mycorrhizal fungi', Soil Biology and Biochemistry, 43(11), 2294-2303.

Kuiters, A. T. (2013) 'Diversity-stability relationships in plant communities of contrasting habitats', Journal of Vegetation Science, 24(3), 453-462.

Kutner, M. H., Nachtsheim, C. J., Neter, J. and Li, W. (2005) Applied linear statistical models, McGraw-Hill Irwin Boston.

Lefsky, M. A., Cohen, W. B., Parker, G. G. and Harding, D. J. (2002) 'Lidar Remote Sensing for Ecosystem Studies: Lidar, an emerging remote sensing technology that directly measures the three-dimensional distribution of plant canopies, can accurately estimate vegetation structural attributes and should be of particular interest to forest, landscape, and global ecologists', BioScience, 52(1), 19-30.

Leigh, J., Fitter, A. H. and Hodge, A. (2011) 'Growth and symbiotic effectiveness of an arbuscular mycorrhizal fungus in organic matter in competition with soil bacteria', FEMS Microbiology Ecology, 76(3), 428-438.

Lewis, R. J., Bello, F., Bennett, J. A., Fibich, P., Finerty, G. E., Götzenberger, L., Hiiesalu, I., Kasari, L., Lepš, J., Májeková, M., Mudrák, O., Riibak, K., Ronk, A., Rychtecká, T., Vitová, A. and Pärtel, M. (2017) 'Applying the dark diversity concept to nature conservation', Conservation Biology, 31(1), 40-47.

Lewis, R. J., Szava $\square$ Kovats, R., Pärtel, M. and Evolution (2016) 'Estimating dark diversity and species pools: an empirical assessment of two methods', Methods in Ecology, 7(1), 104113. 
Liu, Y., Johnson, N. C., Mao, L., Shi, G., Jiang, S., Ma, X., Du, G., An, L. and Feng, H. (2015) 'Phylogenetic structure of arbuscular mycorrhizal community shifts in response to increasing soil fertility', Soil Biology and Biochemistry, 89, 196-205.

Lopatin, J., Dolos, K., Hernández, H., Galleguillos, M. and Fassnacht, F. (2016) 'Comparing generalized linear models and random forest to model vascular plant species richness using LiDAR data in a natural forest in central Chile', Remote Sensing of Environment, 173, 200-210.

Luo, S., De Deyn, G. B., Jiang, B. and Yu, S. (2017) 'Soil biota suppress positive plant diversity effects on productivity at high but not low soil fertility', Journal of Ecology, 105(6), 1766-1774.

Mateo, R. G., Mokany, K. and Guisan, A. (2017) 'Biodiversity Models: What If Unsaturation Is the Rule?', Trends in Ecology \& Evolution, 32(8), 556-566.

McCune, B. (1994) 'Improving community analysis with the Beals smoothing function', Écoscience, 1(1), 82-86.

McCune, B. and Keon, D. (2002) 'Equations for potential annual direct incident radiation and heat load', Journal of Vegetation Science, 13(4), 603-606. random variation in vegetation monitoring data', Journal of Vegetation Science, 19(5), 633-644.

Moeslund, J. E., Brunbjerg, A. K., Clausen, K. K., Dalby, L., Fløjgaard, C., Juel, A. and Lenoir, J. (2017) 'Using dark diversity and plant characteristics to guide conservation and restoration', Journal of Applied Ecology, 54(6), 1730-1741. 
Moeslund, J. E., Zlinszky, A., Ejrnæs, R., Brunbjerg, A. K., Bøcher, P. K., Svenning, J.-C. and Normand, S. (2019) 'Light detection and ranging explains diversity of plants, fungi, lichens, and bryophytes across multiple habitats and large geographic extent', Ecological

Mokany, A. and Shine, R. (2003) 'Competition between tadpoles and mosquito larvae', Oecologia, 135(4), 615-620.

Mueller, G. M. (2011) Biodiversity of fungi: inventory and monitoring methods, Elsevier.

Münzbergová, Z. and Herben, T. (2004) 'Identification of suitable unoccupied habitats in metapopulation studies using co $\square$ occurrence of species', Oikos, 105(2), 408-414.

Nordén, B. and Paltto, H. (2001) 'Wood-decay fungi in hazel wood: species richness correlated to stand age and dead wood features', Biological Conservation, 101(1), 1-8.

Nguyen, N. H., Song, Z., Bates, S. T., Branco, S., Tedersoo, L., Menke, J., Schilling, J. S. and Kennedy, P. G. (2016) 'FUNGuild: an open annotation tool for parsing fungal community datasets by ecological guild', Fungal Ecology, 20, 241-248.

Nadeau, M. B. and Sullivan, T. P. (2015) 'Relationships between plant biodiversity and soil fertility in a mature tropical forest, Costa Rica', International Journal of Forestry Research, 2015, 1-13.

Nordén, B., Ryberg, M., Götmark, F. and Olausson, B. (2004) 'Relative importance of coarse and fine woody debris for the diversity of wood-inhabiting fungi in temperate broadleaf forests', Biological Conservation, 117(1), 1-10.

Noreika, N., Pärtel, M. and Öckinger, E. (2020) 'Community completeness as a measure of restoration success: multiple-study comparisons across ecosystems and ecological groups', Biodiversity and Conservation, 29(13), 3807-3827.

Oksanen, J., Blanchet, F. G., Kindt, R., Legendre, P., Minchin, P. R., O’Hara, R., Simpson, G. L., Solymos, P., Stevens, M. and Wagner, H. (2017) 'vegan: Community Ecology Package. R package version 2.4-3'. 
Pärtel, M., Öpik, M., Moora, M., Tedersoo, L., Szava-Kovats, R., Rosendahl, S., Rillig, M. C., Lekberg, Y., Kreft, H., Helgason, T., Eriksson, O., Davison, J., Bello, F., Caruso, T. and Zobel, M. (2017a) 'Historical biome distribution and recent human disturbance shape the diversity of arbuscular mycorrhizal fungi', New Phytologist, 216(1), 227-238.

Pärtel, M., Szava-Kovats, R. and Zobel, M. (2013) 'Community completeness: linking local and dark diversity within the species pool concept', Folia Geobotanica, 48(3), 307-317.

Pärtel, M., Zobel, M., Öpik, M. and Tedersoo, L. (2017b) 'Global patterns in local and dark diversity, species pool size and community completeness in ectomycorrhizal fungi' in Tedersoo, L., ed., Biogeography of Mycorrhizal Symbiosis, Cham, Switzerland: Springer International Publishing, 395-406.

Pärtel, M., Zobel, M., Zobel, K. and van der Maarel, E. (1996) 'The species pool and its relation to species richness: Evidence from estonian plant communities', Oikos, 75(1), 111-117.

Pellkofer, S., van der Heijden, M. G. A., Schmid, B. and Wagg, C. (2016) 'Soil Communities Promote Temporal Stability and Species Asynchrony in Experimental Grassland Communities', PLOS ONE, 11(2), e0148015.

Penone, C., Allan, E., Soliveres, S., Felipe-Lucia, M. R., Gossner, M. M., Seibold, S., Simons, N. K., Schall, P., van der Plas, F., Manning, P., Manzanedo, R. D., Boch, S., Prati, D., Ammer, C., Bauhus, J., Buscot, F., Ehbrecht, M., Goldmann, K., Jung, K., Müller, J., Müller, J. C., Pena, R., Polle, A., Renner, S. C., Ruess, L., Schönig, I., Schrumpf, M., Solly, E. F., Tschapka, M., Weisser, W. W., Wubet, T. and Fischer, M. (2019) 'Specialisation and diversity of multiple trophic groups are promoted by different forest features', Ecology letters, 22(1), 170-180.

Peura, M., Gonzalez, R. S., Müller, J., Heurich, M., Vierling, L. A., Mönkkönen, M. and Bässler, C. (2016) 'Mapping a 'cryptic kingdom': Performance of lidar derived environmental variables in modelling the occurrence of forest fungi', Remote Sensing of Environment, $186,428-438$.

Pfeifer, N., Mandlburger, G., Otepka, J. and Karel, W. (2014) 'OPALS-A framework for Airborne Laser Scanning data analysis', Computers, Environment and Urban Systems, 45, 125-136.

R Core Team (2019) 'R: A language and environment for statistical computing ', 3.6.0 
Ricotta, C. (2005) 'Through the Jungle of Biological Diversity', Acta Biotheoretica, 53(1), 29-38.

874

Ricotta, C. (2007) 'A semantic taxonomy for diversity measures', Acta Biotheoretica, 55(1), 2333.

Riibak, K., Ronk, A., Kattge, J. and Pärtel, M. (2017) 'Dispersal limitation determines large $\square$ scale dark diversity in Central and Northern Europe', Journal of Biogeography, 44(8), 1770-1780.

Ronk, A., Szava $\square$ Kovats, R. and Pärtel, M. (2015) 'Applying the dark diversity concept to plants at the European scale', Ecography, 38(10), 1015-1025.

Rousk, J., Bååth, E., Brookes, P. C., Lauber, C. L., Lozupone, C., Caporaso, J. G., Knight, R. and Fierer, N. (2010) 'Soil bacterial and fungal communities across a $\mathrm{pH}$ gradient in an arable soil', The ISME journal, 4(10), 1340.

Rousk, J., Brookes, P. C. and Bååth, E. (2009) 'Contrasting soil pH effects on fungal and bacterial growth suggest functional redundancy in carbon mineralization', Applied and Environmental Microbiology, 75(6), 1589-1596.

Salusso, M. M. and Moraña, L. B. (1995) 'Estructura de la comunidad de hongos ectomicorrízicos en bosques de Pinus spp. de Altos La Sierra, Argentina', Revista Chilena de Historia Natural, 68, 509-513.

Sarkar, S. and Margules, C. (2002) 'Operationalizing biodiversity for conservation planning', Journal of Biosciences, 27(4), 299-308.

Scott, C. E., Alofs, K. M. and Edwards, B. A. (2011) 'Putting dark diversity in the spotlight', Trends in Ecology \& Evolution, 26(6), 263-264.

Silvertown, J., Araya, Y. and Gowing, D. (2015) 'Hydrological niches in terrestrial plant communities: a review', Journal of Ecology, 103(1), 93-108.

Solow, A. R. and Polasky, S. (1994) 'Measuring biological diversity', Environmental and Ecological Statistics, 1(2), 95-103.

Staddon, P. L., Thompson, K., Jakobsen, I., Grime, J. P., Askew, A. P. and Fitter, A. H. (2003) 'Mycorrhizal fungal abundance is affected by long-term climatic manipulations in the field', Global Change Biology, 9(2), 186-194. 
912

913

914

915

916

917

918

919

920

921

922

923

924

925

926

927

928

929

930

931

932

933

934

935

936

937

938

939

940

941

942

943

944

945

946

947

948

949

950

951

952

953

Sterkenburg, E., Bahr, A., Brandström Durling, M., Clemmensen, K. E. and Lindahl, B. D. (2015) 'Changes in fungal communities along a boreal forest soil fertility gradient', New Phytologist, 207(4), 1145-1158.

Su, J. G. and Bork, E. W. (2007) 'Characterization of diverse plant communities in Aspen Parkland rangeland using LiDAR data', Applied Vegetation Science, 10(3), 407-416.

Tedersoo, L., Bahram, M., Põlme, S., Kõljalg, U., Yorou, N. S., Wijesundera, R., Ruiz, L. V., Vasco-Palacios, A. M., Thu, P. Q., Suija, A., Smith, M. E., Sharp, C., Saluveer, E., Saitta, A., Rosas, M., Riit, T., Ratkowsky, D., Pritsch, K., Põldmaa, K., Piepenbring, M., Phosri, C., Peterson, M., Parts, K., Pärtel, K., Otsing, E., Nouhra, E., Njouonkou, A. L., Nilsson, R. H., Morgado, L. N., Mayor, J., May, T. W., Majuakim, L., Lodge, D. J., Lee, S. S., Larsson, K.-H., Kohout, P., Hosaka, K., Hiiesalu, I., Henkel, T. W., Harend, H., Guo, L.d., Greslebin, A., Grelet, G., Geml, J., Gates, G., Dunstan, W., Dunk, C., Drenkhan, R., Dearnaley, J., De Kesel, A., Dang, T., Chen, X., Buegger, F., Brearley, F. Q., Bonito, G., Anslan, S., Abell, S. and Abarenkov, K. (2014) 'Global diversity and geography of soil fungi', Science, 346(6213), 1256688.

Thers, H., Brunbjerg, A. K., Læssøe, T., Ejrnæs, R., Bøcher, P. K. and Svenning, J.-C. (2017) 'Lidar-derived variables as a proxy for fungal species richness and composition in temperate Northern Europe', Remote Sensing of Environment, 200, 102-113.

Tonn, N. and Ibáñez, I. (2017) 'Plant-mycorrhizal fungi associations along an urbanization gradient: implications for tree seedling survival', Urban Ecosystems, 20(4), 823-837.

Townsend, C. R., Scarsbrook, M. R. and Dolédec, S. (1997) 'The intermediate disturbance hypothesis, refugia, and biodiversity in streams', Limnology and oceanography, 42(5), 938-949.

Turner, G. D., Lewis, J. D., Mates-Muchin, J. T., Schuster, W. F. and Watt, L. (2009) 'Light availability and soil source influence ectomycorrhizal fungal communities on oak seedlings grown in oak- and hemlock-associated soilsContribution No. 225 of the Louis Calder Center and Biological Station, Fordham University, Armonk, New York', Canadian Journal of Forest Research, 39(7), 1247-1258.

Twieg, B. D., Durall, D. M. and Simard, S. W. (2007) 'Ectomycorrhizal fungal succession in mixed temperate forests', New Phytologist, 176(2), 437-447.

Unterseher, M. and Tal, O. (2006) 'Influence of small scale conditions on the diversity of wood decay fungi in a temperate, mixed deciduous forest canopy', Mycological Research, 110(2), 169-178. 
954
Valdez, J. W., Hartig, F., Fennel, S. and Poschlod, P. (2019) 'The recruitment niche predicts plant community assembly across a hydrological gradient along plowed and undisturbed transects in a former agricultural wetland', Frontiers in plant science, 10, 88.

Vehmas, M., Eerikäinen, K., Peuhkurinen, J., Packalén, P. and Maltamo, M. (2009) 'Identification of boreal forest stands with high herbaceous plant diversity using airborne laser scanning', Forest Ecology and Management, 257(1), 46-53.

Wang, J., Chen, C., Ye, Z., Li, J., Feng, Y. and Lu, Q. (2018) 'Relationships Between Fungal and Plant Communities Differ Between Desert and Grassland in a Typical Dryland Region of Northwest China', Frontiers in Microbiology, 9(2327).

Xiong, S. J., Johansson, M. E., Hughes, F. M. R., Hayes, A., Richards, K. S. and Nilsson, C. (2003) 'Interactive effects of soil moisture, vegetation canopy, plant litter and seed addition on plant diversity in a wetland community', Journal of Ecology, 91(6), 976-986.

Yahr, R., Schoch, C. L. and Dentinger, B. T. (2016) 'Scaling up discovery of hidden diversity in fungi: impacts of barcoding approaches', Philosophical Transactions of the Royal Society B: Biological Sciences, 371(1702), 20150336.

Yang, G., Wagg, C., Veresoglou, S. D., Hempel, S. and Rillig, M. C. (2018) 'How Soil Biota Drive Ecosystem Stability', Trends in Plant Science, 23(12), 1057-1067.

Yang, T., Adams, J. M., Shi, Y., He, J.-s., Jing, X., Chen, L., Tedersoo, L. and Chu, H. (2017) 'Soil fungal diversity in natural grasslands of the Tibetan Plateau: associations with plant diversity and productivity', New Phytologist, 215(2), 756-765.

Zak, D. R., Holmes, W. E., White, D. C., Peacock, A. D. and Tilman, D. (2003) 'Plant diversity, soil microbial communities, and ecosystem function: Are there any links?', Ecology, 84(8), 2042-2050.

Zlinszky, A., Schroiff, A., Kania, A., Deák, B., Mücke, W., Vári, Á., Székely, B. and Pfeifer, N. (2014) 'Categorizing grassland vegetation with full-waveform airborne laser scanning: A feasibility study for detecting Natura 2000 habitat types', Remote Sensing, 6(9), 80568087.

Zobel, M. (2016) 'The species pool concept as a framework for studying patterns of plant diversity', Journal of Vegetation Science, 27(1), 8-18. 
bioRxiv preprint doi: https://doi.org/10.1101/2020.07.02.185553; this version posted January 10,2021 . The copyright holder for this preprint (which was not certified by peer review) is the author/funder, who has granted bioRxiv a license to display the preprint in perpetuity. It is made available under aCC-BY-NC 4.0 International license.

37

994 Zuo, X., Wang, S., Lv, P., Zhou, X., Zhao, X., Zhang, T. and Zhang, J. (2016) 'Plant functional 995 diversity enhances associations of soil fungal diversity with vegetation and soil in the 996 restoration of semiarid sandy grassland', Ecology and Evolution, 6(1), 318-328.

997

998 